\title{
Maternal overweight and obesity are associated with increased risk of type 1 diabetes in offspring of parents without diabetes regardless of ethnicity
}

\author{
Hozan I. Hussen ${ }^{1} \cdot$ Martina Persson $^{2} \cdot$ Tahereh Moradi $^{1,3}$
}

Received: 9 December 2014 / Accepted: 16 March 2015 /Published online: 6 May 2015

(C) Springer-Verlag Berlin Heidelberg 2015

\begin{abstract}
Aims/hypothesis The incidence of type 1 diabetes in children is increasing in Sweden, as is the prevalence of maternal overweight/obesity. Therefore, the aim of this study was to investigate if maternal overweight/obesity increases the risk of type 1 diabetes in offspring of parents with and without diabetes, and of different ethnicities.

Methods The study cohort comprised 1,263,358 children, born in Sweden between 1992 and 2004. Children were followed from birth until diagnosis of type 1 diabetes, emigration, death or end of follow-up in 2009, whichever occurred first. First trimester maternal BMI was calculated $\left(\mathrm{kg} / \mathrm{m}^{2}\right)$. Poisson regression was used to calculate incidence rate ratios (IRRs) with 95\% CI for type 1 diabetes in the offspring.

Results The risk of type 1 diabetes was increased in offspring of parents with any type of diabetes regardless of parental ethnicity. High first trimester maternal BMI was associated with increased risk of type 1 diabetes only in offspring of parents without diabetes (IRR 1.33 [95\% CI 1.20, 1.48]).
\end{abstract}

Tahereh Moradi and Martina Persson contributed equally to this study.

Electronic supplementary material The online version of this article (doi:10.1007/s00125-015-3580-1) contains peer-reviewed but unedited supplementary material, which is available to authorised users.

Tahereh Moradi

tahereh.moradi@ki.se

1 Department of Environmental Medicine, Division of Epidemiology, Unit of Cardiovascular Epidemiology, Karolinska Institutet, Nobels väg 13, Box 210, SE-171 77 Stockholm, Sweden

2 Department of Medicine, Clinical Epidemiology Unit, Karolinska University Hospital, Stockholm, Sweden

3 Centre for Epidemiology and Social Medicine, Health Care Services, Stockholm County Council, Stockholm, Sweden
Conclusions/Interpretation Increasing incidence of type 1 diabetes in children with non-diabetic parents may partly be explained by increasing prevalence of maternal overweight/obesity.

Keywords Country of birth $\cdot$ Incidence $\cdot$ Maternal obesity Maternal overweight $\cdot$ Sweden $\cdot$ Type 1 diabetes

\begin{tabular}{ll}
\multicolumn{2}{l}{ Abbreviations } \\
BW & Birthweight \\
IRR & Incidence rate ratio \\
LGA & Large for gestational age \\
MBR & Medical Birth Registry \\
M\&H Co. & Migration and Health Cohort \\
NPR & National Patient Register \\
PIN & Personal identification number \\
SGA & Small for gestational age
\end{tabular}

\section{Introduction}

Over recent years, the incidence of type 1 diabetes has been increasing worldwide [1], including in Sweden [2]. The reason for such an increase is not fully understood, but there is clear evidence that environmental factors are involved in the aetiology of the disease in genetically susceptible individuals [3]. Numerous environmental factors have been implicated both as triggers and accelerators of immune mediated beta cell destruction occurring pre- and postnatally [4-8].

The effect of a series of parental and prenatal factors on the risk for type 1 diabetes has been explored in several studies [5, 6]. Although type 1 diabetes has been associated with parental diabetes and with a much higher risk conveyed from the father $(6.6 \%)$ than from the mother $(2.3 \%)$ [9], the majority of children developing type 1 diabetes do not have parents with 
diabetes. High maternal BMI has been identified as a risk factor for type 1 diabetes in the offspring in some studies $[10,11]$, while others have reported no such association [12]. One possible explanation for these conflicting results might be an interaction between maternal BMI and parental type 1 diabetes, type 2 diabetes or gestational diabetes. We are not aware of any studies investigating this possible explanation. Furthermore, to our knowledge, no previous study has explored whether the effect of these two potential risk factors for type 1 diabetes in the offspring varies by parental country of birth.

In this Swedish nationwide cohort study, we investigated if the effect of maternal first trimester BMI on the risk for type 1 diabetes in children varies by parental diabetes status and parental country of birth. Maternal diabetes (type 1, type 2 and gestational diabetes) and obesity in pregnancy are both associated with risk of fetal hyperinsulinaemia that in turn may be a risk factor for future diabetes. Therefore, the effect of any type of maternal diabetes in combination with overweight/ obesity for the risk of type 1 diabetes in the offspring was analysed as well as stratified by type of maternal diabetes.

\section{Methods}

Database Data was derived from the newly established Migration and Health Cohort (M\&H Co.) [13]. This cohort was created by individual record-linkage between Swedish national registries using personal identification numbers (PIN). In the present study we used the following registries included in the M\&H Co.: (1) The Swedish total populations register, in which we retrieved demographic information such as sex, date of birth, country of birth, and date of immigration and emigration [14]; (2) The Swedish Medical Birth Registry (MBR), which contains data on more than $98 \%$ of births in Sweden since 1973 [15]; (3) The National Patient Register (NPR), which contains data on inpatient care and diagnoses based on the ICD [16, 17]; (4) The Cause of Death Register, which provides information on the date of death [18]; and (5) The Multi-Generation Register, which contains information on biological links between children and their parents via PIN [19]. The latest extensive validation of MBR concluded that the quality of data in the register is high [15]. The quality and completeness of data in the NPR is evaluated on a regular basis by the Swedish National Board of Health and Welfare. The result of the latest validation of NPR showed that the diagnoses are valid in 80-95\% [16, 17] (see Electronic supplementary material [ESM] Methods for further details).

The study was approved by the Regional Ethical Committees in Stockholm, Sweden (Dnr. 2009/2033-32).

Study cohort The study population comprised 1,263,358 infants and children between 0 and 18 years of age, born and living in Sweden any time between 1992 and 2004. We performed a step by step exclusion in our cohort. We first excluded individuals with any congenital malformation $(n=$ $42,498 ; 3.36 \%)$, followed by multiple births $(n=37,113$; $2.94 \%)$, and delivered before the 28 th $(n=1,565 ; 0.13 \%)$ or after the 43rd $(n=435 ; 0.04 \%)$ completed week of gestation. We further excluded children with missing data on birthweight (BW) $(n=3,655,0.31 \%)$, gestational age $(n=1,326,0.11 \%)$ and infants with $\mathrm{BW}>6 \mathrm{SD}$ above or below the mean $(n=$ $3)$. Records with missing data on mode of delivery $(n=28)$, or with extreme values on maternal age $(<13$ years, $n=1)$, first trimester maternal weight ( $<40$ or $\geq 200 \mathrm{~kg} ; n=544,0.05 \%$ ) and maternal height $(<120$ or $\geq 200 \mathrm{~cm} ; n=35)$ were also excluded. The final cohort included $1,176,155$ individuals.

Follow-up The cohort members were followed from the date of birth until the date of diagnosis of type 1 diabetes according to the ninth and tenth Swedish versions of the ICD codes (ICD-9 [www.icd9data.com/2007/Volume1]: 250 before 1997; ICD-10 [www.who.int/classifications/icd/en/]: E10 from 1997 onwards), emigration, death or end of follow-up (31 December 2009), whichever occurred first.

Definition of the exposures The main exposure of interest was first trimester pregnancy BMI, calculated as $\mathrm{kg} / \mathrm{m}^{2}$. Women were categorised into three groups $(\mathrm{BMI}<18.5,18.5 \leq \mathrm{BMI}$ $<25,25 \leq \mathrm{BMI}<30, \mathrm{BMI} \geq 30$ ) according to the WHO classification of BMI cut-offs [20]. First trimester maternal weight was measured at the first antenatal clinic visit, which occurs before 15 weeks of gestation in more than $95 \%$ of all pregnancies [15]. Information about maternal height and smoking was recorded by recall. Information on first trimester maternal BMI was available in $83.97 \%$ of the women. We performed a sensitivity analysis on a sample of women $(n=281,701)$ with two consecutive births in 1992 and 2004. The distribution of overweight and obesity in the second pregnancy was similar in women with and without data on BMI in the first pregnancy ( $25.7 \%$ and $10.2 \%$ vs $25.5 \%$ and $10.1 \%$, respectively).

Data on diagnoses of maternal and paternal diabetes was obtained from the NPR, according to the Swedish version of the ICD, as maternal diabetes (pre-gestational type 1 diabetes, type 2 diabetes, or other specified or unspecified types of diabetes, ICD-9: 250 and 648A, and ICD-10: E10, E11, E13, E14 and O240-O243), gestational diabetes (ICD-9: 648W and ICD-10: O244) and paternal diabetes (type 1 diabetes, type 2 diabetes or other specified or unspecified types of diabetes, ICD-9: 250, and ICD-10: E10, E11, E13, E14). ICD-9 does not include specific codes for different types of diabetes and we did not have access to biochemical data such as presence of autoantibodies or level of glycaemic control. As type 1 diabetes is most commonly diagnosed in childhood and type 2 is rare in children, we categorised diabetes as type 1 diabetes if diagnosed before 30 years of age and as type 2 diabetes if diagnosed after 30 years of age. 
Parental country of birth was first defined as either Sweden (both parents born in Sweden) or outside Sweden (both parents born abroad and labelled as 'foreign'). Owing to similar lifestyles in the Nordic countries, we further regrouped parents as Nordic and non-Nordic.

Other exposures of interest were maternal age categorised into four age groups, mode of delivery, maternal smoking habits at the first antenatal clinic visit and during the first trimester, and size of offspring at birth. The highest attained parental education in years was used as an indicator for socioeconomic position. Based on the Swedish reference curves for normal fetal growth, infants were categorised as: appropriate for gestational age (AGA) defined as BW between the 10th and 90th percentile, small for gestational age (SGA): BW $<10$ th percentile and large for gestational age (LGA): BW $>90$ th percentile [21].

Definition of outcome Children ( $0-18$ years) diagnosed with type 1 diabetes according to the ninth and tenth Swedish versions of the ICD (ICD-9: 250 before 1996, and ICD-10: E10 after 1997) were identified in the NPR.

Statistical analyses Using Poisson regression models, we calculated incidence rate ratios (IRRs) and 95\% CIs to estimate the effect of maternal early pregnancy BMI on the risk of type 1 diabetes in the offspring. The analyses were also stratified by parental diabetes (yes/no) and parental country of birth. The effect of first trimester maternal overweight/ obesity and different types of parental diabetes for the risk of type 1 diabetes in the offspring was also assessed. Due to limitations in power, these analyses were only performed within the Nordic cohort.

All risk estimates were adjusted for sex, age of the child at follow-up in 6 year intervals ( $0-5,6-11$ and $12-18$ years) and birth cohort (1992-1995, 1996-1999 and 2000-2004). The IRRs were additionally adjusted for maternal diabetes, paternal diabetes, first trimester maternal BMI, maternal age, gestational age and maternal smoking in a mutually exclusive manner (i.e. in the analysis concerning maternal diabetes, the estimates were adjusted for paternal diabetes, first trimester maternal BMI, maternal age, gestational age, mode of delivery, maternal smoking and highest attained level of parental education in addition to sex, age and birth cohort of the child). Interactions were tested using likelihood ratio tests. Given that our main aim was to investigate if the effect of maternal first trimester BMI on the risk for type 1 diabetes in children varies by parental diabetes status and parental place of birth, we did not adjust for multiple comparisons in our analysis. For all analyses, $p<0.05$ was considered statistically significant.

All analyses were performed using Statistical Analysis System (SAS) software, version 9.3 (SAS Institute, Cary, NC, USA).

\section{Results}

A total of 5,771 children were diagnosed with type 1 diabetes during the study period. Of those, 4,879, 5,155 and 322 children had parents born in Sweden, within the Nordic countries, and outside the Nordic countries, respectively. Two hundred and ninety-four children had one parent born within and one parent born outside the Nordic countries. On average, the age at onset of type 1 diabetes was similar in offspring of parents born in Nordic countries (mean $\pm \mathrm{SD} ; 7.8 \pm 3.92$ ), and in offspring of non-Nordic parents (mean $\pm \mathrm{SD} ; 7.1 \pm 3.79$ ).

Parental diabetes (type 1 diabetes, type 2 diabetes or gestational diabetes) and high first trimester maternal BMI were both associated with increased risk of type 1 diabetes in the offspring regardless of parental country of birth (Table 1 and ESM Table 1). Parental type 1 diabetes was associated with the greatest risk.

Parental diabetes and risk of type 1 diabetes in the offspring Offspring of Nordic mothers with diabetes (type 1 diabetes, type 1 diabetes or gestational diabetes) had about three times higher risk for type 1 diabetes compared with offspring of non-diabetic mothers in multivariable models adjusted for paternal diabetes, first trimester maternal BMI, maternal age, gestational age, smoking habits in early pregnancy, parental years of education, mode of delivery, sex, age and year of birth cohort (Table 1). In the analysis stratified by type of parental diabetes, offspring of mothers with type 1 diabetes had six times higher IRR compared with offspring of mothers without diabetes regardless of the mother's country of birth. Offspring of Nordic mothers with gestational or type 2 diabetes had an almost doubled risk compared with offspring of mothers without diabetes (Table 1). In offspring of nonNordic mothers however, there was no association between maternal type 2 or gestational diabetes and risk of type 1 diabetes in the offspring.

Offspring of Nordic fathers with type 1 diabetes had an almost eight times increased risk for type 1 diabetes compared with offspring of fathers without diabetes. Paternal type 2 diabetes was associated with a doubled risk of type 1 diabetes in the offspring (Table 1).

\section{Maternal overweight and obesity in early pregnancy and} risk of type 1 diabetes in the offspring Increased first trimester maternal BMI was associated with increased risk of type 1 diabetes in the offspring, regardless of parental country of birth and after multivariable adjustment for potential confounders ( $p$ for trend: 0.001 and 0.008 for Nordic and nonNordic parents, respectively). Compared with offspring of normal weight mothers, offspring of obese mothers of Nordic origin had a $25 \%$ higher IRR for type 1 diabetes. Offspring of obese mothers born outside the Nordic countries had a $67 \%$ higher IRR for type 1 diabetes (Table 1). 
Table 1 Risk of type 1 diabetes among children and young adults (0-18 years) born in Sweden between years 1992 and 2004 and followed until 2009 , by parental migration status and by potential type 1 diabetes risk factors

\begin{tabular}{|c|c|c|c|c|c|c|}
\hline \multirow[t]{2}{*}{ Variable } & \multicolumn{3}{|c|}{ Both parents Nordic ${ }^{a}$} & \multicolumn{3}{|c|}{ Both parents non-Nordic ${ }^{\mathrm{b}}$} \\
\hline & No. of parents & Children with TID & $\operatorname{IRR}^{\mathrm{c}}(95 \% \mathrm{CI})$ & No. of parents & Children with TID & $\operatorname{IRR}^{\mathrm{c}}(95 \% \mathrm{CI})$ \\
\hline \multicolumn{7}{|l|}{ Mother } \\
\hline Diabetic $^{\mathrm{d}}$ & 16,368 & 285 & $3.17 *(2.80,3.58)$ & 5,221 & 21 & $1.47(0.94,2.31)$ \\
\hline T1DM & 5,210 & 169 & $6.19 *(5.30,7.23)$ & 385 & 6 & $5.80 *(2.57,13.06)$ \\
\hline $\mathrm{T} 2 \mathrm{DM}+$ gestational & 11,158 & 116 & $1.85^{*}(1.53,2.23)$ & 4,836 & 15 & $1.13(0.67,1.92)$ \\
\hline Non-diabetic & 932,056 & 4,870 & 1 (reference) & 123,146 & 301 & 1 (reference) \\
\hline \multicolumn{7}{|l|}{ Father } \\
\hline Diabetic $^{e}$ & 12,890 & 374 & $5.27 *(4.74,5.86)$ & 4,084 & 24 & $2.11 *(1.39,3.21)$ \\
\hline T1DM & 7,525 & 294 & $7.59 *(6.74,8.54)$ & 831 & 6 & $2.72 *(1.21,6.11)$ \\
\hline $\mathrm{T} 2 \mathrm{DM}$ & 5,365 & 80 & $2.47 *(1.98,3.08)$ & 3,253 & 18 & $1.95 *(1.20,3.14)$ \\
\hline Non-diabetic & 935,534 & 4,781 & 1 (reference) & 124,283 & 298 & 1 (reference) \\
\hline \multicolumn{7}{|c|}{ First trimester maternal BMI $\left(\mathrm{kg} / \mathrm{m}^{2}\right)$} \\
\hline $30+$ & 70,243 & 441 & $1.25^{*}(1.13,1.38)$ & 9,902 & 33 & $1.67 *(1.13,2.49)$ \\
\hline $25-29.9$ & 186,823 & 1,054 & $1.11 *(1.03,1.19)$ & 27,566 & 80 & $1.43 *(1.07,1.90)$ \\
\hline $18.5-24.9$ & 529,717 & 2,756 & 1 (reference) & 58,011 & 121 & 1 (reference) \\
\hline$<18.5$ & 19,293 & 93 & $0.89(0.73,1.10)$ & 3,994 & 13 & $1.54(0.87,2.74)$ \\
\hline Missing & 142,348 & 811 & $1.06(0.98,1.15)$ & 28,894 & 75 & $1.17(0.86,1.58)$ \\
\hline \multicolumn{7}{|l|}{ Maternal age (years) } \\
\hline $35+$ & 141,588 & 739 & $1.10(0.88,1.39)$ & 19,111 & 45 & $0.87(0.45,1.65)$ \\
\hline $30-34$ & 303,911 & 1,539 & $1.06(0.84,1.33)$ & 33,217 & 94 & $1.05(0.57,1.93)$ \\
\hline $25-29$ & 344,636 & 1,949 & $1.09(0.87,1.36)$ & 41,340 & 91 & $0.82(0.45,1.50)$ \\
\hline $20-24$ & 142,417 & 847 & $1.09(0.87,1.37)$ & 30,065 & 80 & $1.00(0.54,1.83)$ \\
\hline$<20$ & 15,872 & 81 & 1 (reference) & 4,634 & 12 & 1 (reference) \\
\hline \multicolumn{7}{|l|}{ Birthweight $^{f}$} \\
\hline SGA $(<10$ th P) & 192,940 & 1,058 & $0.99(0.92,1.06)$ & 38,729 & 89 & $0.84(0.65,1.09)$ \\
\hline LGA (>90th P) & 357,387 & 1,884 & $0.91(0.86,0.97)$ & 32,454 & 76 & $0.81(0.61,1.06)$ \\
\hline AGA (10-90th P) & 398,097 & 2,213 & 1 (reference) & 57,184 & 157 & 1 (reference) \\
\hline \multicolumn{7}{|l|}{ Smoking $^{g}$} \\
\hline Yes & 136,719 & 683 & $0.74 *(0.67,0.80)$ & 12,543 & 31 & $0.94(0.65,1.36)$ \\
\hline 1-9 cigarettes/day & 89,727 & 453 & $0.77 *(0.70,0.85)$ & 9,047 & 26 & $1.08(0.72,1.62)$ \\
\hline $10+$ cigarettes/day & 46,992 & 230 & $0.69 *(0.60,0.79)$ & 3,496 & 5 & $0.53(0.22,1.30)$ \\
\hline Non-smoker & 766,006 & 4,250 & 1 (reference) & 107,493 & 269 & 1 (reference) \\
\hline Unknown & 45,699 & 222 & $0.85 *(0.74,0.98)$ & 8,331 & 22 & $1.03(0.65,1.62)$ \\
\hline \multicolumn{7}{|l|}{ Parental years of education } \\
\hline $0-9$ & 19,986 & 102 & $1.00(0.82,1.22)$ & 16,140 & 33 & $0.71(0.49,1.03)$ \\
\hline $10-12$ & 211,063 & 1,389 & $1.14 *(1.07,1.22)$ & 26,373 & 72 & $0.96(0.74,1.26)$ \\
\hline 13 or more & 717,067 & 3,664 & 1 (reference) & 83,058 & 216 & 1 (reference) \\
\hline Unknown & 308 & 0 & - & 2,796 & 1 & $0.46(0.06,3.32)$ \\
\hline \multicolumn{7}{|l|}{ Caesarean delivery } \\
\hline Yes & 119,665 & 697 & $1.06(0.97,1.15)$ & 14,930 & 40 & $1.08(0.77,1.51)$ \\
\hline No & 828,759 & 4,458 & 1 (reference) & 113,437 & 282 & 1 (reference) \\
\hline \multicolumn{7}{|l|}{ Birth cohort } \\
\hline 1992-1995 & 345,787 & 2,562 & $0.84 *(0.78,0.91)$ & 40,992 & 133 & $0.71 *(0.53,0.96)$ \\
\hline
\end{tabular}


Table 1 (continued)

\begin{tabular}{|c|c|c|c|c|c|c|}
\hline \multirow[t]{2}{*}{ Variable } & \multicolumn{3}{|c|}{ Both parents Nordic ${ }^{\mathrm{a}}$} & \multicolumn{3}{|c|}{ Both parents non-Nordic ${ }^{\mathrm{b}}$} \\
\hline & No. of parents & Children with TID & $\operatorname{IRR}^{\mathrm{c}}(95 \% \mathrm{CI})$ & No. of parents & Children with TID & $\operatorname{IRR}^{\mathrm{c}}(95 \% \mathrm{CI})$ \\
\hline 1996-1999 & 261,637 & 1,519 & $0.94(0.87,1.02)$ & 37,603 & 101 & $0.77(0.57,1.04)$ \\
\hline 2000-2004 & 341,000 & 1,074 & 1 (reference) & 49,772 & 88 & 1 (reference) \\
\hline
\end{tabular}

${ }^{a}$ Both parents born in Sweden, Norway, Denmark, Finland or Iceland

${ }^{\mathrm{b}}$ None of the parents born in Sweden, Norway, Denmark, Finland or Iceland

${ }^{\mathrm{c}}$ IRRs and $95 \%$ CIs are mutually adjusted for parental diabetes, maternal BMI, maternal age, size for gestational age, smoking at enrolment, parental level of education, mode of delivery, sex, age at follow-up and birth cohort

${ }^{\mathrm{d}}$ Mother with type 1 or type 2 or gestational diabetes

${ }^{\mathrm{e}}$ Father with type 1 or type 2 diabetes

${ }^{\mathrm{f}}$ Birthweight by gestational age based on the Swedish reference curves for normal fetal growth

${ }^{\mathrm{g}}$ Maternal smoking habits at enrolment

${ }^{*} p<0.05$

AGA, appropriate for gestational age; $\mathrm{P}$, percentile; T1DM, type 1 diabetic; T2DM, type 2 diabetic

The observed increased risk of type 1 diabetes in the offspring associated with first trimester maternal BMI was, however, confined to children of non-diabetic parents (Table 2). The same pattern was observed if parents were born in a Nordic country or in a non-Nordic country (Table 2). Although this observed increased risk was more prominent in offspring of parents born outside the Nordic countries, the $p$ value testing this variation by parental country of birth and diabetes status was not statistically significant. The $p$ values for interaction between first trimester maternal BMI (continuous variable) and maternal diabetic status were $<0.0001,<0.0001$ and 0.81 in the whole cohort, Nordic cohort and non-Nordic cohort, respectively. None of the $p$ values for the paternal diabetic status were significant.

First trimester maternal overweight and obesity were associated with a decreased risk of type 1 diabetes in the offspring of mothers with any type of diabetes (maternal BMI $\geq 30$ : IRR 0.58 [95\% CI 0.41, 0.82]; Table 2). The reduced risk was confined however, to offspring of diabetic mothers born in a Nordic country (Table 2). Within the Nordic cohort, the proportion of women with any type of diabetes increased with the BMI category. In particular, the proportions of women with type 2 or gestational diabetes increased with higher BMI. In analyses stratified by type of maternal diabetes (Table 3), the risk for type 1 diabetes in the offspring was significantly reduced in children born to mothers with overweight/obesity and type 2 diabetes (overweight mothers with type 2 diabetes: IRR 0.20 [95\% CI 0.04, 0.93]; obese mothers with type 2 diabetes: IRR 0.23 [95\% $0.07,0.77]$ ) (Table 3). First trimester maternal overweight/obesity had no significant impact on the risk for type 1 diabetes in children born to mothers with type 1 or gestational diabetes (Table 3 ). Nine hundred and thirty-eight offspring of mothers with missing data on BMI were diagnosed with type 1 diabetes.
Maternal age, maternal smoking, parental socioeconomic position, mode of delivery and infant size at birth, and risks of type 1 diabetes in the offspring Maternal age, mode of delivery and infant size at birth had no significant impact on the risk of type 1 diabetes in the offspring in either cohort. In offspring of Nordic mothers, maternal smoking in early pregnancy was associated with a decreased risk of type 1 diabetes in the offspring. A low level of parental socioeconomic position was associated with a slightly increased risk of type 1 diabetes in the offspring (Table 1).

\section{Discussion}

This nationwide cohort study, demonstrates that paternal and maternal diabetes (type 1 diabetes, type 2 diabetes and gestational diabetes) and first trimester maternal overweight/ obesity are associated with increased risks of type 1 diabetes in the offspring, regardless of parental country of birth. A novel finding in this study is that high maternal BMI in the first trimester of pregnancy was only associated with an increased risk of type 1 diabetes in offspring of parents without diabetes.

The primary strength of the present study is its cohort design based on national data. The large sample size enabled us to assess the association of first trimester maternal BMI and risk of type 1 diabetes in the offspring after stratification by parental diabetes. Even though the study was based on national data spanning over 13 years, power was limited in some of the sub-analyses within the non-Nordic cohort.

BMI was calculated based on measured weight but selfreported height. The uncertainty of self-reported data may bias our findings but as individuals tend to over report their height, any potential bias would most likely lead to an 
Table 2 Risk of type 1 diabetes among children and young adults (0-18 years), born between 1992 and 2004 in Sweden and followed until 2009, by first trimester maternal BMI, parental migration status and parental diabetes

\begin{tabular}{|c|c|c|c|c|c|c|}
\hline \multirow{2}{*}{$\begin{array}{l}\text { Parental migration } \\
\text { status and diabetic } \\
\text { status }\end{array}$} & \multicolumn{6}{|c|}{ First trimester maternal BMI } \\
\hline & $\begin{array}{l}\text { Underweight } \\
<18.5 \mathrm{~kg} / \mathrm{m}^{2} \\
\operatorname{IRR}^{\mathrm{a}}(95 \% \mathrm{CI})\end{array}$ & $\begin{array}{l}\text { Normal weight } \\
18.5-24.9 \mathrm{~kg} / \mathrm{m}^{2} \\
\text { IRR }\end{array}$ & $\begin{array}{l}\text { Overweight } \\
25-29.9 \mathrm{~kg} / \mathrm{m}^{2} \\
\operatorname{IRR}^{\mathrm{a}}(95 \% \mathrm{CI})\end{array}$ & $\begin{array}{l}\text { Obese } \\
\geq 30 \mathrm{~kg} / \mathrm{m}^{2} \\
\operatorname{IRR}^{\mathrm{a}}(95 \% \mathrm{CI})\end{array}$ & $\begin{array}{l}p \text { value } \\
\text { for trend }\end{array}$ & $\begin{array}{l}\text { Unknown BMI } \\
\text { IRR }^{\mathrm{a}}(95 \% \mathrm{CI})\end{array}$ \\
\hline \multicolumn{7}{|l|}{ Total population } \\
\hline \multicolumn{7}{|l|}{ Diabetic } \\
\hline Mother $^{\mathrm{b}}$ & $0.23(0.03,1.64)$ & 1 & $0.88(0.67,1.17)$ & $0.58 *(0.41,0.82)$ & 0.2 & $0.97(0.72,1.32)$ \\
\hline Father $^{\mathrm{c}}$ & $1.06(0.58,1.95)$ & 1 & $1.08(0.85,1.38)$ & $1.07(0.77,1.49)$ & 0.5 & $0.83(0.61,1.11)$ \\
\hline Mother \& father & NA & 1 & $1.90(0.64,5.63)$ & $0.96(0.27,3.40)$ & 0.2 & $1.05(0.29,3.80)$ \\
\hline \multicolumn{7}{|l|}{ Non-diabetic } \\
\hline Mother $^{\mathrm{b}}$ & $0.90(0.74,1.09)$ & 1 & $1.12 *(1.04,1.20)$ & $1.35 *(1.22,1.49)$ & $<0.0001$ & $1.02(0.95,1.11)$ \\
\hline Father $^{\mathrm{c}}$ & $0.85(0.69,1.04)$ & 1 & $1.12 *(1.04,1.20)$ & $1.31 *(1.19,1.45)$ & 0.0002 & $1.05(0.97,1.13)$ \\
\hline Mother \& father & $0.87(0.71,1.07)$ & 1 & $1.11 *(1.03,1.19)$ & $1.33 *(1.20,1.48)$ & 0.0005 & $1.03(0.95,1.12)$ \\
\hline \multicolumn{7}{|c|}{ Nordic (including Sweden) } \\
\hline \multicolumn{7}{|l|}{ Diabetic } \\
\hline Mother $^{\mathrm{b}}$ & $0.33(0.05,2.38)$ & 1 & $0.92(0.68,1.24)$ & $0.57 *(0.39,0.84)$ & 0.4 & $1.14(0.82,1.58)$ \\
\hline Father $^{\mathrm{c}}$ & $0.96(0.47,1.95)$ & 1 & $1.10(0.85,1.43)$ & $1.13(0.80,1.59)$ & 0.4 & $0.93(0.68,1.28)$ \\
\hline Mother \& father & NA & 1 & $2.01(0.57,7.14)$ & $1.00(0.24,4.25)$ & 0.2 & $2.26(0.52,9.78)$ \\
\hline \multicolumn{7}{|l|}{ Non-diabetic } \\
\hline Mother $^{\mathrm{b}}$ & $0.91(0.74,1.12)$ & 1 & $1.12 *(1.04,1.21)$ & $1.33 *(1.19,1.47)$ & 0.0003 & $1.05(0.97,1.15)$ \\
\hline Father $^{\mathrm{c}}$ & $0.88(0.71,1.09)$ & 1 & $1.12 *(1.04,1.21)$ & $1.29 *(1.16,1.43)$ & 0.0004 & $1.08(0.99,1.18)$ \\
\hline Mother \& father & $0.90(0.72,1.12)$ & 1 & $1.12 *(1.03,1.21)$ & $1.31 *(1.17,1.46)$ & 0.0008 & $1.06(0.97,1.16)$ \\
\hline \multicolumn{7}{|l|}{ Non-Nordic } \\
\hline \multicolumn{7}{|l|}{ Diabetic } \\
\hline Mother $^{\mathrm{b}}$ & NA & 1 & $1.40(0.42,4.66)$ & $1.32(0.34,5.13)$ & 0.5 & $1.13(0.33,3.83)$ \\
\hline Father $^{\mathrm{c}}$ & $10.8^{*}(2.36,49.41)$ & 1 & $3.78 *(1.17,12.22)$ & $2.34(0.50,10.83)$ & 0.03 & $1.35(0.33,5.55)$ \\
\hline Mother \& father & NA & 1 & NA & NA & NA & NA \\
\hline \multicolumn{7}{|l|}{ Non-diabetic } \\
\hline Mother $^{\mathrm{b}}$ & $1.60(0.90,2.85)$ & 1 & $1.44 *(1.07,1.94)$ & $1.76^{*}(1.16,2.67)$ & 0.007 & $1.17(0.86,1.61)$ \\
\hline Father $^{\mathrm{c}}$ & $1.23(0.64,2.35)$ & 1 & $1.34(0.99,1.81)$ & $1.73 *(1.15,2.60)$ & 0.028 & $1.19(0.87,1.62)$ \\
\hline Mother \& father & $1.26(0.66,2.42)$ & 1 & $1.33(0.97,1.81)$ & $1.69 *(1.09,2.61)$ & 0.037 & $1.15(0.83,1.59)$ \\
\hline
\end{tabular}

${ }^{\text {a }}$ IRRs and 95\% CIs are adjusted for maternal age, size for gestational age, smoking at enrolment, parental level of education, mode of delivery, sex, age at follow-up and birth cohort

${ }^{\mathrm{b}}$ Diabetic or non-diabetic mother regardless of father

${ }^{\mathrm{c}}$ Diabetic or non-diabetic father regardless of mother

$* p<0.05$

NA, not applicable (no power)

underestimation of risks associated with first trimester maternal overweight and obesity. The observed risks associated with first trimester maternal overweight and obesity may also be underestimated if women with missing information on BMI were more overweight/obese than women with data on BMI. However, as the distribution of BMI was very similar in women with two consecutive pregnancies regardless of whether BMI was recorded in the first pregnancy, we consider this risk to be very small.
High weight gain in pregnancy has previously been identified as a risk factor for type 1 diabetes in the offspring [10, 22]. In the present study, we did not have access to reliable data on weight gain in pregnancy or information on paternal BMI. The impact of these variables on the risk for type 1 diabetes in the offspring could therefore not be assessed. Patients with any type of diabetes were identified based on ICD codes. We lacked specific ICD codes before 1997 (ICD-9) to distinguish between type 1 diabetes and type 2 diabetes and 


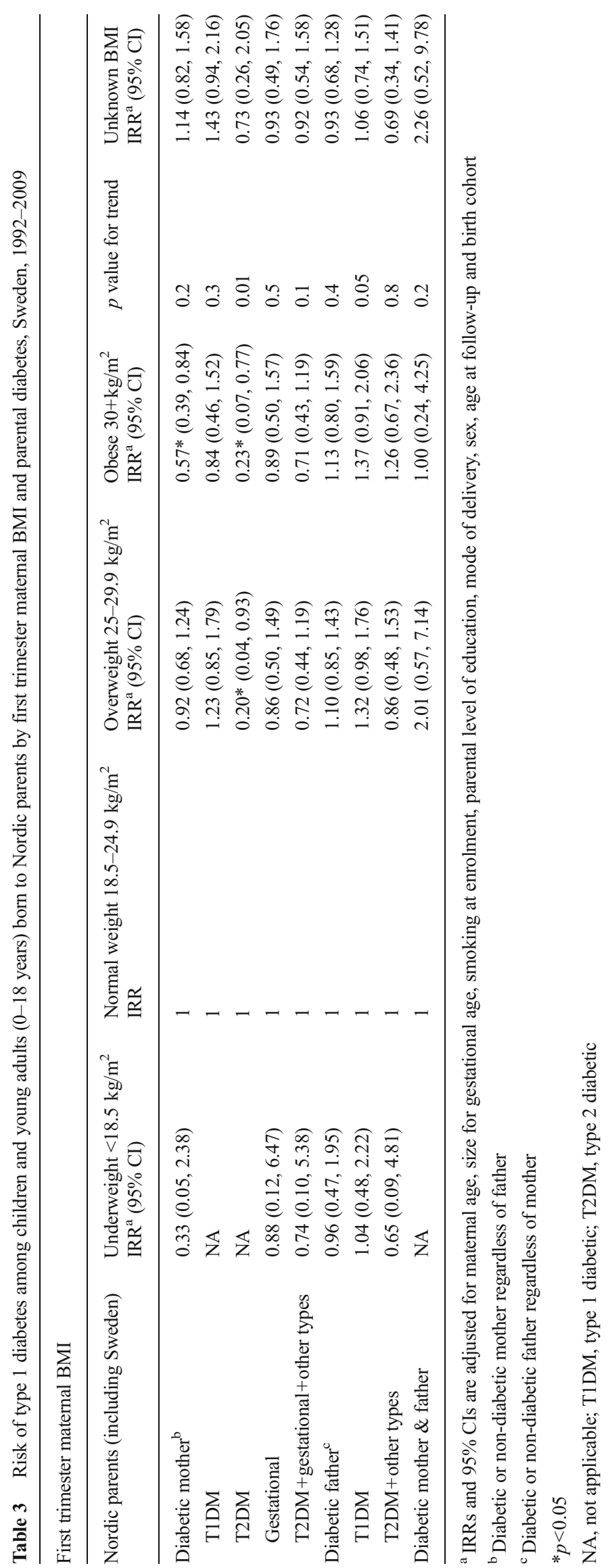


we did not have access to any biochemical data (autoantibodies, level of glycaemic control). However, as type 2 diabetes is very uncommon in young children and the oldest child in our cohort with a non-specific diagnosis of diabetes was 5 years old, we considered these cases as type 1 diabetes.

Since the youngest child in our study was 5 years old at the end of follow-up, we may have missed cases of diabetes diagnosed at a later age. Furthermore, since the aetiology behind type 1 diabetes very early in life is more often genetic rather than environmental [23], the observed risk of type 1 diabetes associated with maternal overweight and obesity may have been underestimated.

The potential misclassification of type of diabetes is more of a concern in older individuals who were diagnosed with ICD-9 codes. We attempted to disentangle the types of parental diabetes through age limitations; we considered it likely that any case of unspecified diabetes would be type 1 diabetes if diagnosed before the age of 30 years and type 2 diabetes if diagnosed after 30 years of age. In addition, the results of a sensitivity analysis confined to individuals living before and after the introduction of ICD-10 were similar [24]. Furthermore, a validation study of the clinical diagnoses of diabetes and its classification has shown that, about $95 \%$ of the diabetes diagnoses in the medical records were correct and in accordance with the WHO criteria [25]. In accordance with the results of previous studies $[9,26]$, we found increased risks of type 1 diabetes in offspring of mothers with type 1 diabetes. Our finding of an increased risk of type 1 diabetes in the offspring of mothers with type 2 diabetes or gestational diabetes, also reported by others $[9,27]$, could possibly be attributed to epigenetic effects of an abnormal intrauterine environment.

Our analysis demonstrates that in the Nordic population, paternal type 1 diabetes is associated with a higher risk of type 1 diabetes in the offspring than maternal type 1 diabetes. The finding of an almost eightfold increased risk of type 1 diabetes in the offspring of fathers with type 1 diabetes is in line with previous studies [28, 29]. In contrast, among non-Nordic parents, mothers with type 1 diabetes transferred a greater risk of type 1 diabetes to their offspring than fathers. However, the low number of offspring in this group does not allow any firm conclusions.

LGA has previously been demonstrated to be associated with increased risk of type 1 diabetes in the offspring across different populations [5, 30]. BW, adjusted for gestational age, is correlated significantly with the risk of type 1 diabetes in the offspring [31, 32]. In the present study, however, we did not find any association between infant size at birth and risk of type 1 diabetes in either cohort. Maternal age was not a risk factor for type 1 diabetes in the offspring. This finding is in line with some previous studies [33,34], whereas others have reported increased risk with advanced maternal age $[6,11]$. The reasons behind these diverging results are unclear and need to be explored in future studies.
Consistent with previous studies $[6,33,35]$, we found a reduced risk of type 1 diabetes in offspring of mothers who smoked in early pregnancy. The mechanism behind the apparent protective effect of smoking for the development of diabetes in the offspring is unclear. Preeclampsia, more common in non-smokers [36], has been associated with increased risk of type 1 diabetes in the offspring $[37,38]$. Thus, the reduced risk of type 1 diabetes in offspring of smoking mothers could be due to immunological factors associated with preeclampsia [6]. Indeed, preeclampsia was more common among non-smokers than smokers in the present study.

Mode of delivery has been associated with increased risk of type 1 diabetes in the offspring [6]. In this study, however, we were not able to confirm this association neither in the Nordic nor in the non-Nordic cohort.

Our finding of an increased risk of type 1 diabetes in the offspring of overweight and obese mothers has been reported in some previous studies [10,11], while others did not report this association $[12,33]$. In the present study, the combined effect of first trimester maternal obesity and parental diabetes for the risk of type 1 diabetes in the offspring was also investigated. Novel findings include that the increased risk is confined to offspring of parents without diabetes. The finding that first trimester maternal obesity was a risk factor for type 1 diabetes only in offspring of parents without diabetes, and with no further increment in risk in offspring of parents with diabetes, clearly suggests that heredity for type 1 diabetes is the strongest risk factor of the two for development of type 1 diabetes in the next generation.

Maternal hyperglycaemia and maternal obesity are both associated with fetal hyperinsulinaemia, a potential risk factor for the development of diabetes in the offspring. The finding of a reduced risk for type 1 diabetes in offspring of overweight and obese mothers with type 2 diabetes was therefore unexpected. However, one could speculate that this observation is a reflection of the different genetic backgrounds for type 1 and type 2 diabetes. There is a strong correlation between BMI and fat mass in early pregnancy [39]. Given the different metabolic effects of an increased subcutaneous and visceral fat mass [40], it is possible that the risk for type 1 diabetes in the offspring differs with type of maternal obesity. This could, however, not be explored in the present study.

Maternal overweight and obesity are associated with increased insulin resistance and enhanced transfer of glucose and other nutrients across the placenta, stimulating fetal insulin secretion [41]. Offspring of overweight and obese mothers have significantly increased fat mass and signs of insulin resistance already at birth [42]. Furthermore, maternal prepregnancy BMI is correlated with fetal insulin resistance and per cent body fat in the newborn [42]. In addition, data from animal models indicate that hyperinsulinaemia in utero may lead to mal-programming of metabolic and neuroendocrine networks and increased risk for obesity and diabetes 
in the offspring [43]. Against this background, it is possible that epigenetic factors in the intrauterine environment of obese mothers initiate beta cell stress, metabolic dysregulation and earlier onset of type 1 diabetes in genetically susceptible individuals.

High maternal BMI is often associated with high BW in the offspring [44], and high BW in turn is associated with increased risk of type 1 diabetes $[32,45]$. In this context, it is interesting to note that certain HLA genotypes associated with low risk for type 1 diabetes recently have been associated also with overweight and obesity. Furthermore, the proportion of newly diagnosed children with a low risk HLA profile (HLA-DQ A1*05:01-B1*02:01/A1*05:01-B1*02:01) as opposed to the high risk profile (HLA-DQ A1*05:01-B1*02:01/ $\left.A 1^{*} 03: 01-B 1^{*} 03: 02\right)$, is increasing over time, concomitant with an increasing incidence of overweight and obesity at diagnosis [46].

In conclusion, this population-based study from Sweden demonstrates significantly increased risks of type 1 diabetes in offspring of both mothers and fathers with diabetes and regardless of parental migration background. The highest risks were noted in offspring of mothers and fathers with type 1 diabetes. Furthermore, maternal overweight and obesity in early pregnancy were associated with increased risk of type 1 diabetes in the offspring of parents without diabetes. Prevention of overweight and obesity in women of reproductive age may contribute to a decreased incidence of type 1 diabetes.

Acknowledgements The authors appreciate the help from Statistics Sweden and the National Board of Health and Welfare, which provided them with data.

Funding This work was supported by Swedish Research Council for Health, Working Life and Welfare (FORTE, project no. 2014-0279), and The Ministry of Higher Education and Scientific Research-Kurdistan Regional Government/Iraq.

Duality of interest The authors declare that there is no duality of interest associated with this manuscript.

Contribution statement $\mathrm{HIH}$ designed the research, drafted the manuscript, analysed data and interpreted the results. MP and TM designed the research, interpreted the results critically, reviewed and edited the manuscript. TM handled research data and funding. All authors have approved the final version to be published. TM and HIH are responsible for the integrity of the work as a whole.

\section{References}

1. WHO Multinational Project for Childhood Diabetes (DIAMOND) Research Group (2006) Incidence and trends of childhood type 1 diabetes worldwide 1990-1999. Diabet Med 23:857-866

2. Hussen HI, Persson M, Moradi T (2013) The trends and the risk of type 1 diabetes over the past 40 years: an analysis by birth cohorts and by parental migration background in Sweden. BMJ Open 3: e003418

3. Stene LC, Gale EA (2013) The prenatal environment and type 1 diabetes. Diabetologia 56:1888-1897

4. Knip M, Veijola R, Virtanen SM, Hyoty H, Vaarala O, Akerblom HK (2005) Environmental triggers and determinants of type 1 diabetes. Diabetes 54(Suppl 2):S125-S136

5. Cardwell CR, Carson DJ, Patterson CC (2005) Parental age at delivery, birth order, birth weight and gestational age are associated with the risk of childhood type 1 diabetes: a UK regional retrospective cohort study. Diabet Med 22:200-206

6. Dahlquist G, Kallen B (1992) Maternal-child blood group incompatibility and other perinatal events increase the risk for early-onset type 1 (insulin-dependent) diabetes mellitus. Diabetologia 35:671675

7. Hypponen E (2010) Vitamin D and increasing incidence of type 1 diabetes-evidence for an association? Diabetes Obes Metab 12: 737-743

8. Filippi CM, von Herrath MG (2008) Viral trigger for type 1 diabetes: pros and cons. Diabetes 57:2863-2871

9. Dahlquist G, Blom L, Tuvemo T, Nystrom L, Sandstrom A, Wall S (1989) The Swedish childhood diabetes study — results from a nine year case register and a one year case-referent study indicating that type 1 (insulin-dependent) diabetes mellitus is associated with both type 2 (non-insulin-dependent) diabetes mellitus and autoimmune disorders. Diabetologia 32:2-6

10. Rasmussen T, Stene LC, Samuelsen SO et al (2009) Maternal BMI before pregnancy, maternal weight gain during pregnancy, and risk of persistent positivity for multiple diabetes-associated autoantibodies in children with the high-risk HLA genotype: the MIDIA study. Diabetes Care 32:1904-1906

11. D'Angeli MA, Merzon E, Valbuena LF, Tirschwell D, Paris CA, Mueller BA (2010) Environmental factors associated with childhood-onset type 1 diabetes mellitus: an exploration of the hygiene and overload hypotheses. Arch Pediatr Adolesc Med 164: $732-738$

12. Arkkola T, Kautiainen S, Takkinen HM et al (2011) Relationship of maternal weight status and weight gain rate during pregnancy to the development of advanced beta cell autoimmunity in the offspring: a prospective birth cohort study. Pediatr Diabetes 12:478-484

13. Beiki O, Stegmayr B, Moradi T (2011) Country reports: Sweden. In: Razum O, Spallek J, Reeske A, Arnold M (eds) Migrationsensitive cancer registration in Europe. Lang, Pieterlen, pp 106-123

14. Johannesson I (2002) The total population register of statistics Sweden. New possibilities and better quality. Statistics Sweden, Örebro

15. The Swedish Centre for Epidemiology (2003) The Swedish Medical Birth Register: a summary of content and quality www. socialstyrelsen.se/Lists/Artikelkatalog/Attachments/10655/2003112-3_20031123.pdf.

16. Ludvigsson JF, Andersson E, Ekbom A et al (2011) External review and validation of the Swedish national inpatient register. BMC Public Health 11:450

17. Socialstyrelsen [The National Board of Health and Welfare] (2009) Kvalitet och innehåll i patientregistret [Quality and content of the patient register]. Available from http://www.socialstyrelsen.se/ english, accessed 22 Sept 2014

18. Socialstyrelsen (2007) Causes of death, The National Board of Health and Welfare, Centre for Epidemiology. Official Statistics of Sweden

19. The Multi-Generation Registry (2001) Bakgrundsfakta till befolknings-ochvälfärdsstatistik. Statistska Centralbyrån, Örebro [article in Swedish]

20. James PT, Leach R, Kalamara E, Shayeghi M (2001) The worldwide obesity epidemic. Obes Res 9(Suppl 4):S228-S233 
21. Marsal K, Persson PH, Larsen T, Lilja H, Selbing A, Sultan B (1996) Intrauterine growth curves based on ultrasonically estimated foetal weights. Acta Paediatr 85:843-848

22. McKinney PA, Parslow R, Gurney K, Law G, Bodansky HJ, Williams DR (1997) Antenatal risk factors for childhood diabetes mellitus; a case-control study of medical record data in Yorkshire, UK. Diabetologia 40:933-939

23. Ziegler AG, Bonifacio E, Group B-BS (2012) Age-related islet autoantibody incidence in offspring of patients with type 1 diabetes. Diabetologia 55:1937-1943

24. Hussen HI, Yang D, Cnattingius S, Moradi T (2013) Type I diabetes among children and young adults: the role of country of birth, socioeconomic position and sex. Pediatr Diabetes 14:138-148

25. Rolandsson O, Norberg M, Nystrom L et al (2012) How to diagnose and classify diabetes in primary health care: lessons learned from the Diabetes Register in Northern Sweden (DiabNorth). Scand J Prim Health Care 30:81-87

26. Algert CS, McElduff A, Morris JM, Roberts CL (2009) Perinatal risk factors for early onset of type 1 diabetes in a 2000-2005 birth cohort. Diabet Med 26:1193-1197

27. Wagener DK, Sacks JM, LaPorte RE, Macgregor JM (1982) The Pittsburgh study of insulin-dependent diabetes mellitus. Risk for diabetes among relatives of IDDM. Diabetes 31:136-144

28. Warram JH, Krolewski AS, Gottlieb MS, Kahn CR (1984) Differences in risk of insulin-dependent diabetes in offspring of diabetic mothers and diabetic fathers. N Engl J Med 311:149-152

29. Harjutsalo V, Reunanen A, Tuomilehto J (2006) Differential transmission of type 1 diabetes from diabetic fathers and mothers to their offspring. Diabetes 55:1517-1524

30. Larsson K, Elding-Larsson H, Cederwall E et al (2004) Genetic and perinatal factors as risk for childhood type 1 diabetes. Diabetes Metab Res Rev 20:429-437

31. Dahlquist G, Bennich SS, Kallen B (1996) Intrauterine growth pattern and risk of childhood onset insulin dependent (type I) diabetes: population based case-control study. BMJ 313:1174-1177

32. Dahlquist GG, Pundziute-Lycka A, Nystrom L (2005) Birthweight and risk of type 1 diabetes in children and young adults: a population-based register study. Diabetologia 48:1114-1117

33. Robertson L, Harrild K (2010) Maternal and neonatal risk factors for childhood type 1 diabetes: a matched case-control study. BMC Public Health 10:281

34. Toschke AM, Ehlin A, Koletzko B, Montgomery SM (2007) Paternal smoking is associated with a decreased prevalence of type
1 diabetes mellitus among offspring in two national British birth cohort studies (NCDS and BCS70). J Perinat Med 35:43-47

35. Haynes A, Cooper MN, Bower C, Jones TW, Davis EA (2014) Maternal smoking during pregnancy and the risk of childhood type 1 diabetes in Western Australia. Diabetologia 57:469-472

36. Duffus GM, MacGillivray I (1968) The incidence of pre-eclamptic toxaemia in smokers and non-smokers. Lancet 1:994-995

37. Dahlquist GG, Patterson C, Soltesz G (1999) Perinatal risk factors for childhood type 1 diabetes in Europe. The EURODIAB Substudy 2 Study Group. Diabetes Care 22:1698-1702

38. McKinney PA, Parslow R, Gurney KA, Law GR, Bodansky HJ, Williams R (1999) Perinatal and neonatal determinants of childhood type 1 diabetes. A case-control study in Yorkshire, U.K. Diabetes Care 22:928-932

39. Sewell MF, Huston-Presley L, Amini SB, Catalano PM (2007) Body mass index: a true indicator of body fat in obese gravidas. J Reprod Med 52:907-911

40. Jarvie E, Hauguel-de-Mouzon S, Nelson SM, Sattar N, Catalano PM, Freeman DJ (2010) Lipotoxicity in obese pregnancy and its potential role in adverse pregnancy outcome and obesity in the offspring. Clin Sci (Lond) 119:123-129

41. Brandt S, Moss A, Lennerz B et al (2014) Plasma insulin levels in childhood are related to maternal factors - results of the Ulm Birth Cohort Study. Pediatr Diabetes 15:453-463

42. Catalano PM, Presley L, Minium J, Hauguel-de Mouzon S (2009) Fetuses of obese mothers develop insulin resistance in utero. Diabetes Care 32:1076-1080

43. Plagemann A (2008) A matter of insulin: developmental programming of body weight regulation. J Matern Fetal Neonatal Med 21: $143-148$

44. Stamnes Koepp UM, Frost Andersen L, Dahl-Joergensen K, Stigum H, Nass O, Nystad W (2012) Maternal pre-pregnant body mass index, maternal weight change and offspring birthweight. Acta Obstet Gynecol Scand 91:243-249

45. Stene LC, Magnus P, Lie RT, Sovik O, Joner G, Norwegian childhood Diabetes Study G (2001) Birth weight and childhood onset type 1 diabetes: population based cohort study. BMJ 322: 889-892

46. Carlsson A, Kockum I, Lindblad B et al (2012) Low risk HLA-DQ and increased body mass index in newly diagnosed type 1 diabetes children in the Better Diabetes Diagnosis study in Sweden. Int J Obes (Lond) 36:718-724 